\title{
WHO veteran heads up Canadian public health
}

\author{
Cite as: CMAJ 2017 March 13;189:E418-9. doi: 10.1503/cmaj.1095394
}

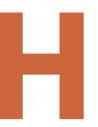

ow international health emergencies are handled holds lessons for

Canadian public health on a range of fronts, from infectious diseases to opioid misuse. That's the view of Dr. Theresa Tam, who became Canada's Chief Public Health Officer on an interim basis when Dr. Gregory Taylor retired in December 2016. A competition now underway will determine who will eventually fill the spot, but neither the Privy Council Office, which appoints the position, nor the Public Health Agency of Canada (PHAC) has provided a timeline.

Tam has served on three World Health Organization (WHO) emergency committees: Ebola, Middle East respiratory syndrome (MERS) and poliovirus. Emergency committees are convened under the International Health Regulations (IHR) to decide whether disease outbreaks constitute "public health emergencies of international concern" and what measures should be taken to deal with them. Canada has had members on all six of the emergency committees established since the IHR came into force in 2007.

Emergency committee members do not represent their countries, Tam explained. She was selected for her background in field epidemiology, travel health, emergency medicine and pandemic preparedness. A UK-trained physician, Tam is a specialist in pediatrics and infectious diseases and an author of dozens of published studies. She began her federal government career with the former Centre for Infectious Disease Prevention and Control. At PHAC, she has been responsible for briefs dealing with immunization and respiratory infections, and the Centre for Emergency Preparedness and Response. She served as federal cochair of the Pandemic Influenza Committee of Canada and as cochair of the Canadian Immunization Committee, as well as on many WHO committees and task forces.
The WHO emergency committees on which she has served had to make the tough decision about whether a disease outbreak was an emergency, following a "systematic and rigorous" process. In the case of MERS, the committee decided it wasn't an emergency, but with Ebola, the committee decided it was.

Ebola held lessons for other public health decisions. "The world was looking at Ebola as if it was something we knew before," said Tam. "Nobody could see how fast that epidemic was going to grow based on the information we had." This new perspective informed the decision to declare Zika virus an emergency "not on the basis of what was known, but what was not known. You can't base your decision on what you know about a disease, because it could go in a different direction."

"The type of approach that is laid out quite nicely in IHR has been really helpful in helping me think through how to handle similar issues in Canada," she added. Those situations were not limited to infectious diseases. She mentioned food-borne illnesses that cross provincial boundaries, the crisis in opioid misuse and antimicrobial resistance. PHAC is now developing a pan-Canadian framework for antimicrobial resistance, which Tam says is one of her top priorities.

"Most of these health problems are complex, requiring intersectoral cooperation, but you would respond in a way similar to the way you would respond to an infectious disease outbreak," she said.

She compared the IHR emergency process to Canada's Pan-Canadian Public Health Network, established in 2005. It brings together a wide variety of public health organizations, government ministries and agencies, academics, as well as the Council of Chief Medical Officers of Health. While much of the network's focus has been health promotion, disease prevention and preparedness, it would pro-

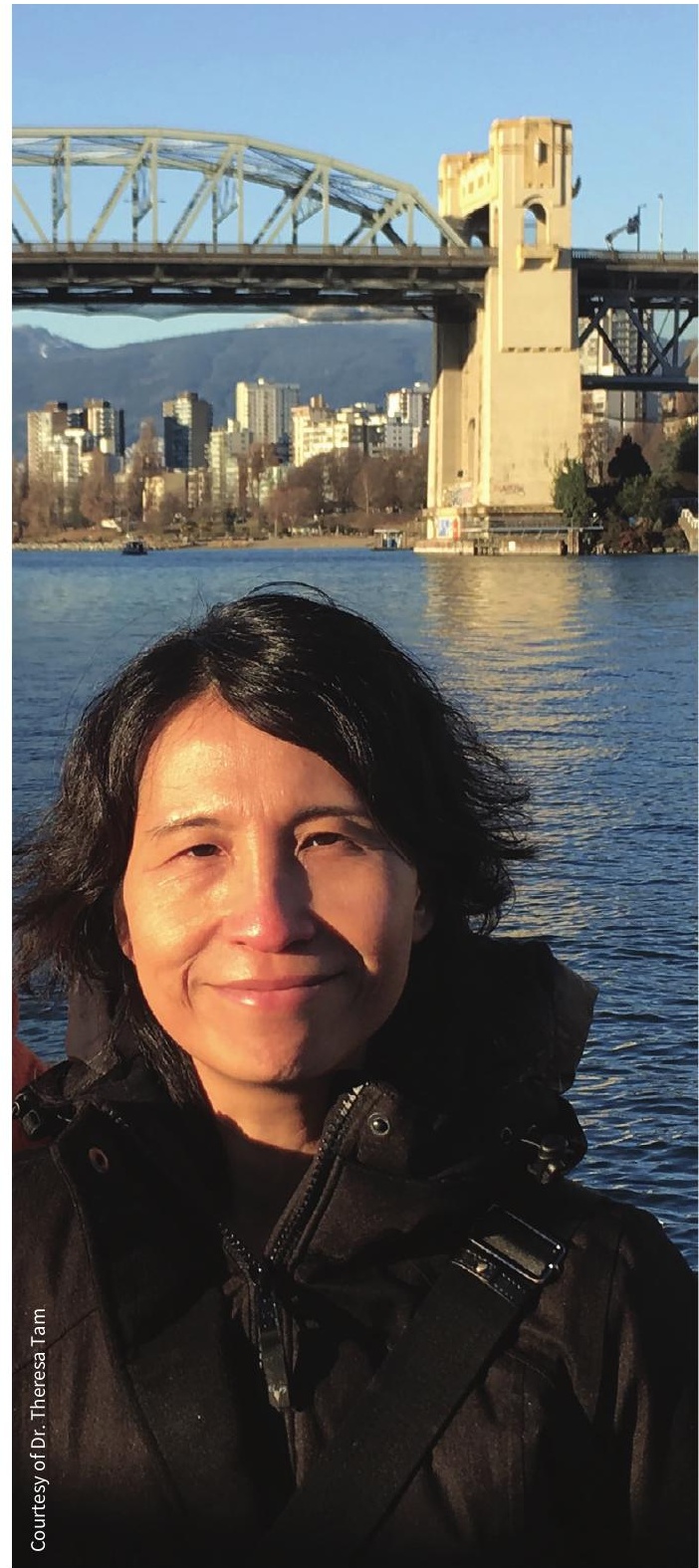

Dr. Theresa Tam is Canada's interim Chief Public Health Officer after serving as its deputy.

vide the mechanism to deal with a national emergency.

Tam sees value in the Canadian government's commitment to tackle diseases like Ebola and MERS that are unlikely to arrive on our shores. (For Ebola, the government 
promised $\$ 108$ million to boost response capacity in West Africa and to develop the vaccine.) "The world has to work in solidarity to learn to manage these outbreaks. As we help on the ground in whichever way to build capacity or develop vaccines - it can be used for other emerging infectious diseases."

For example, she said the National
Microbiology Laboratory's vaccine-development platform that yielded the Ebola vaccine can be used to create vaccines for other pathogens. "There are not that many facilities like our laboratory in the world, and we have to contribute to that effort."

She is also wary that emerging diseases can happen here. "Diseases appear on a fairly regular basis, and the potential for spread through international travel and trade is increasing." She said that helping other countries build a strong public health system ends up helping us. "That is actually critical in a globalized world. Any capacity gain will serve not only other countries, but Canada as well."

Carolyn Brown, Ottawa, Ontario 